\title{
Portable Biometric System of High Sensitivity Absorption Detection
}

\author{
Der Chin Chen \\ FENG CHIA University, \\ Taiwan, R.O.C
}

\section{Introduction}

The traditional bio-chemical detecting methods include two methods. One method is to use a meter to measure the change of voltage that is converted from the bio-chemical energy. The other method is to use the testing agent applied on the sample. For example, a chemical testing agent or testing paper can be used to measure the density of a target object in the sample. After which, a quantitative analysis can be done by using some optical techniques. The first method is easy, compact, fast, and no pollution generated by the testing agent or paper. However, its disadvantages include low precision and not suitable for repeated testing. The second method is good in the quantitative analysis and suitable for mass detection. It is widely used in different automatic detecting equipments in the bio-chemical industry. Also, it is the major method used in current medical and bio-chemical related fields. But, its disadvantages include the testing device is complex, it is not suitable for dynamic testing, it will cause certain pollution from the testing agent, and its operation is complicated. The basic principle of the optical technique is to measure the absorbance as a scale to determine the density of a specific colored object in the sample. Furthermore, it can be classified into the following methods, such as colorimetric analysis method, spectral analysis method, fluorescent analysis method, turbidity analysis method, etc. The devices about all these methods are quite similar to the conventional spectrometer.

The current commercial spectrometer for bio-chemical testing has many kinds. The large spectrometer is expensive and occupies a huge space. However, the micro spectrometer is light-weighted, small, fast, easy to operate, suitable for mass detection and non-expensive [1-2]. But, its precision and sensitivity is not good due to the technical limitation of its micro light detector. So, it is still not suitable for most bio-chemical testing. The conventional spectrometer main specification was shown in Table 1.

Referring to Fig. 1, it illustrates the structure of a conventional micro spectrometer. It contains two parts, namely the optical system and the electrical system (not shown). The optical system includes a traditional light source having the tungsten filament, a condenser and filter, spatial filter, a self-focusing blazed reflection grating, and a linear CCD detector. The traditional light source provides an enough light (or beam) for the micro spectrometer and will cover the wavelength range of the linear CCD detector. The condenser can collected the incoming light into the micro spectrometer. Light from the input fiber enters the optical bench through this condenser. Also, the numerical aperture (N.A.) value of the condenser should match with the one of the input fiber. The filter is a device that restricts light to pre-determined wavelength 
regions. The function of a self-focusing blazed reflection grating is to separate the light with different wavelength ranges and to focus the reflected lights to the linear CCD detector. The linear CCD detector can detect the light intensity and distribution and then converted into electrical signals for further analog output processing. Each pixel on the linear CCD detector responds to the wavelength of light that strikes it, creating a spectral response.

No matter the conventional spectrometer is the large one or the micro one, the container must be the standard rectangular quartz made container (the bottom is one centimeter square and the depth is one centimeter, so the volume is $1 \mathrm{cc}$ as shown Fig. 2). Two sizes are available; $3.5 \mathrm{ml}$ (standard) and $1.5 \mathrm{ml}$ (semi-micro). All containers have a $10 \mathrm{~mm}$ path length and are $45 \mathrm{~mm}$ high. Therefore, they require sample's volume is relative large. The optical requirement is as follows: parallelism $<30$ arc sec, perpendicularity $<10$ arc min and flatness $<2 \lambda @ 632.8 \mathrm{~nm}$. Assume that the user is located in an area or country where it is under the danger of Severe Acute Respiratory Syndrome (briefly called SARS hereafter) virus and H1N1. If the user (of a medical organization) needs to collect the sputum of a patient, the user has to collect at least $1 \mathrm{cc}$ to conduct a bio-chemical testing. In case the user only collects $0.5 \mathrm{cc}$ of the patient's sputum, the test cannot be done by the conventional spectrometer because the volume is fewer than the require minimum $1 \mathrm{cc}$. Hence, the user will miss the best time for determine whether this patient is a SARS patient or not. It not only is disadvantageous for the patient, but also increases the uncertainty and panic for the society.However, if the user simply reduces the required volume down to $0.5 \mathrm{cc}$, it will cause another problem that the sensitivity of the entire system becomes one half of the original one. Therefore, the testing becomes unreliable. Besides, because different coloring agents have different light absorption characteristics, an additional filter has to be added on the conventional light source so that a particular wavelength range can be selected. However, after using the filter for a long period, it will cause the over-heating problem.

Thus, the disadvantages of the conventional spectrometer can be summarized as follows: [a] the required volume of the sample is relatively large, [b] the entire optical system is complex and expensive, [c] the sensitivity of one-path penetration through the sample is low, and[d] the conventional tungsten-typed light source needs additional filters to solve the overheating problem. Due to drawbacks mentioned above, we are motivated to explore new technique named portable biometric system of high sensitivity absorption detection. The new technique covers three systems: the double optical path absorbance biometric system that can be applied in practices, the multi optical path absorbance biometric system and the multi-color sensor measurement system which are in experimental stage. The measured sample by the first two systems is blue latex and the measured sample by the last one is color plastic ball.

\begin{tabular}{|l|l|}
\hline Sensor range: & 200-1100 $\mathrm{nm}$ \\
\hline Sensor: & 2048-element linear silicon CCD array \\
\hline Gratings: & 14 gratings; UV through Shortwave NIR \\
\hline Entrance aperture: & $5,10,25,50,100$ or $200 \mathrm{~mm}$ wide slits or fiber (no slit) \\
\hline filters: & Installed long-pass and band-pass filters \\
\hline Focal length: & $\mathrm{f} / 4,42 \mathrm{~mm}$ (input); $68 \mathrm{~mm}$ (output) \\
\hline Optical resolution: & $0.3 \sim 10.0 \mathrm{~nm}$ FWHM (depending on grating and size of entrance aperture) \\
\hline
\end{tabular}

Table 1. Conventional spectrometer main specifications. 


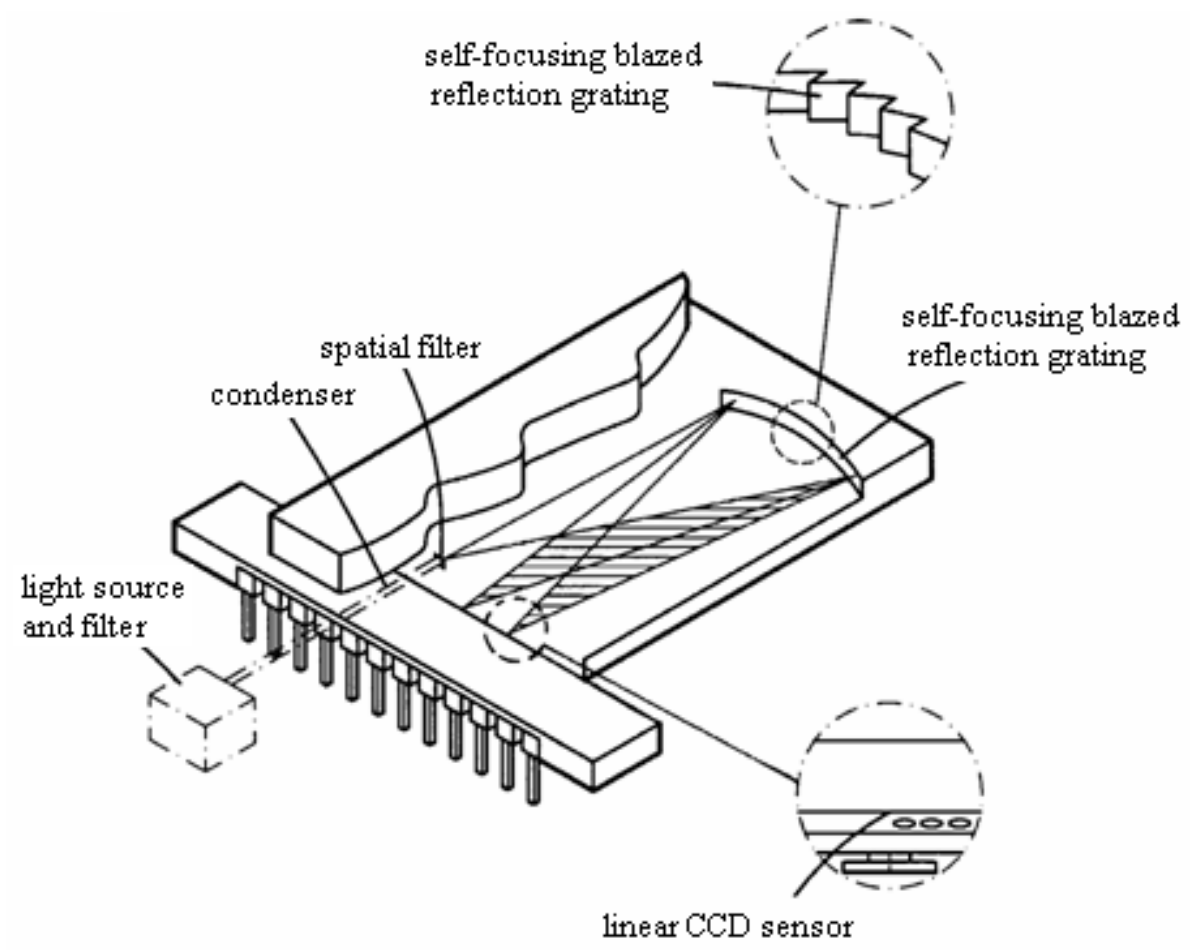

Fig. 1. Spectrometer with components.

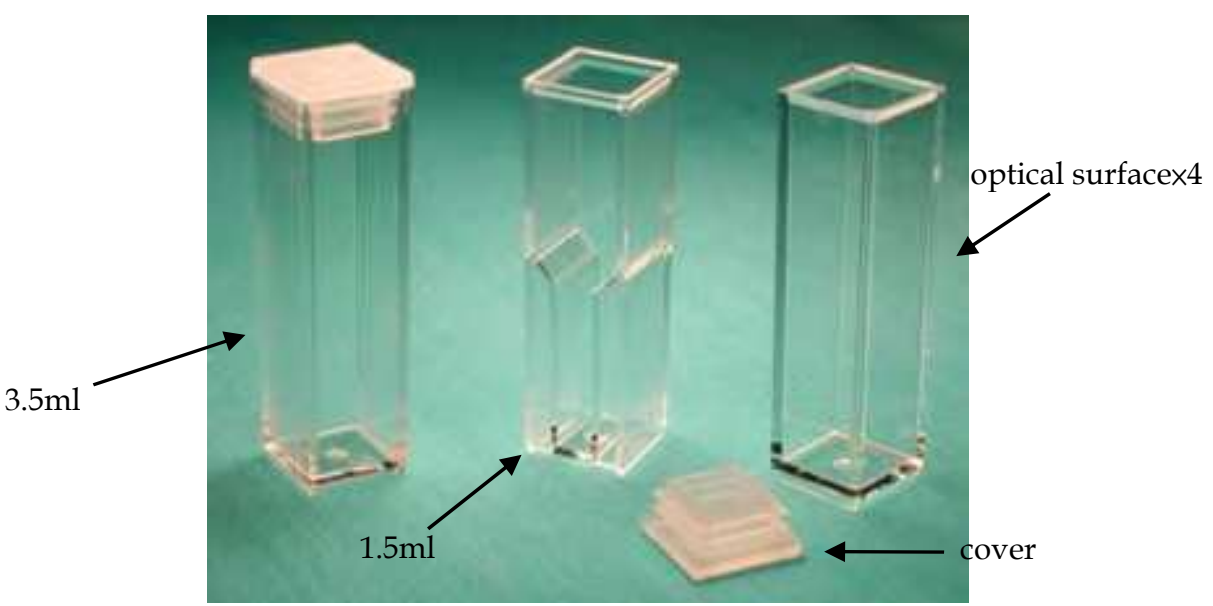

Fig. 2. Containers are designed to fit all standard instruments. 


\section{Principle}

The portable biometric system presented in this paper involves two principles. The first principle is the biological principle of Enzyme-Linked Immuno Sorbent Assay (ELISA), the second principle is the electro-optical technique used in this system. Performing an ELISA involves at least one antibody with specificity for a particular antigen. The sample with an unknown amount of antigen is immobilized on a polystyrene microtiter plate either nonspecifically (via adsorption to the surface) or specifically (via capture by another antibody specific to the same antigen, in a "sandwich" ELISA). After the antigen is immobilized the detection antibody is added, forming a complex with the antigen. The detection antibody can be covalently linked to an enzyme, or can itself be detected by a secondary antibody which is linked to an enzyme through bioconjugation. The enzyme use in this system is the gold colloid, which has the property of light absorption. The system detects the intensity change of the visible collimated beam, which passes through the sample solution twice, to know the absorbance of the sample solution. The detective object of this system is the gold colloid that the sample produces after the biochemical reaction-immunology. There is a certain relationship between the color of the gold colloid and its concentration. By measuring the particular wavelength of the optical absorbance of the gold colloid, the concentration of the waiting measured sample can be obtained. The concentration of chemical compositions can be further obtained by establishing the relationship table between the optical absorbance of the gold colloid and the concentration of chemical compositions. From the Beer-Lambert law (as shown Fig. 3), the amount of radiation absorbed is represented in the follow equation: $A=\varepsilon b c$, where $\mathrm{A}$ is absorbance (since $\left.A=\log 10\left(\frac{P_{o}}{P}\right)\right) ; \mathrm{P}_{0}$ is the beam of radiation entering the sample solution while $\mathrm{P}$ is the beam of radiation exiting the sample); $\varepsilon$ is the molar absorptivity with units of $\mathrm{L} \mathrm{mol}^{-1} \mathrm{~cm}-1$; $b$ is the path length of the sample-that is, the path length of the container in which the sample is contained, we will express this measurement in centimeter; $\mathrm{c}$ is the concentration of the compound in the solution, expressed in mol $\mathrm{L}^{-1}$. From above we can know that increasing the path length of the solution or increasing the monochromatic optical path in the waiting-measured sample solution can increase the optical absorbance. The processes of double optical path increase the opportunities that the collimated beam is absorbed which raise the detection sensitivity of this system. The method that allows the visible collimated beam to pass by the sample solution twice is the use of prism array.

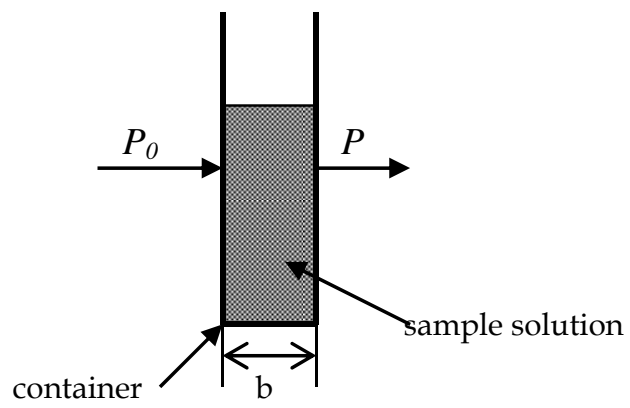

Fig. 3. The absorbance of sample solution. 


\section{The portable biometric system}

The systematic construction of portable double optical path absorbance biometric system is shown in Fig. 4[3-4]. Increasing the path length of the sample increases the amount of samples needed resulting in increased testing cost. But sometimes we are absolutely not able to obtain so many samples. However, this defect can be improved by using the double optical path device. The biometric system includes : (a) optical transmitter/receiver unit,(b) micro container as shown in Fig. 5, and (c) double optical path unit as shown in Fig. 6. The optical transmitter/receiver unit includes LED light source, current driver, LED's selector, photodiode, operator amplifier, and signal processor. The double optical path unit includes input fiber, cube beam splitter, two way fiber, collimator, micro container, output fiber, and corner prism array. With regard to the micro container, it has a circular recess with predetermined depth $\mathrm{H}$ and with a predetermined diameter $\mathrm{D}$ for receiving a sample. The micro container has a first surface and a second surface. The micro container is made from transparent optical plastic plate by UV laser lithography. This optical plate is made by PMMA. The micro container is a circular hole with diameter (D) between 4 to $6 \mathrm{~mm}$ and a depth $(\mathrm{H})$ between 1 to $5 \mu \mathrm{m}$. The corner cube array is disposed near the first surface of the micro container. This corner cube array has several micro corner cubes so as to reflect an incoming beam back along its original path of the incoming beam. The collimator is disposed at a position outside the second surface of the micro container. The beam splitting

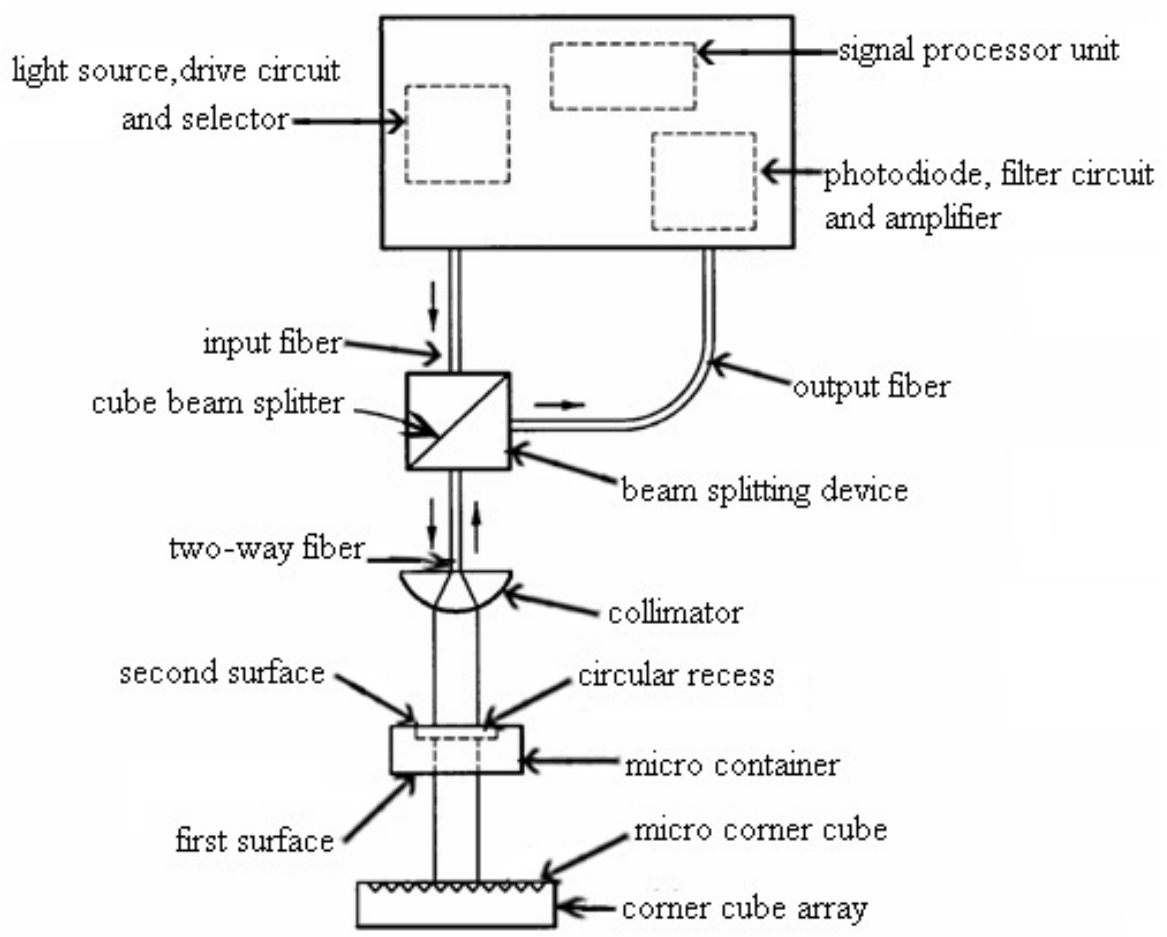

Fig. 4. Portable double optical path absorbance biometric system. 
device has a cube beam splitter, an input fiber, an output fiber, and a two-way fiber. The light source selector is used for providing a first beam that has a predetermined wavelength range and intensity.

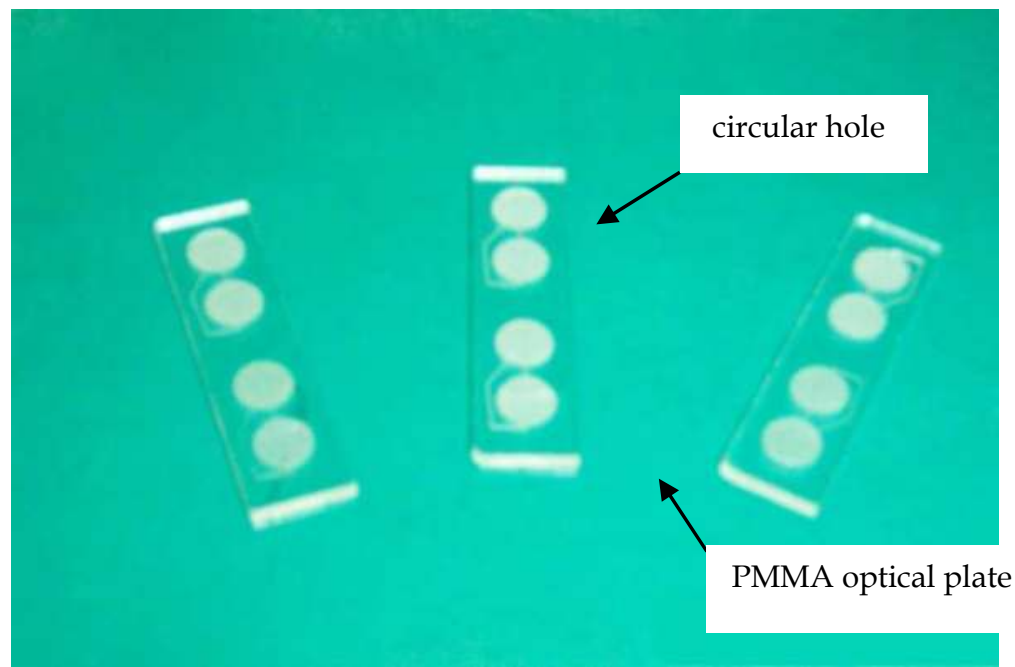

Fig. 5. Micro container.

The light source selector includes an electrical switch, a LED array that has a plurality of different colored LEDs, a plurality of middle fibers, and a light coupler to guide a selected colored LED light into the input fiber so that the first light beam having a desired wavelength, as shown in Fig. 7. Therefore, there are many wavelength ranges that can be chosen. Its advantage is to allow the user to execute one of many different bio-chemical tests by selecting a suitable wavelength range, such as to detect the density of blood sugar,

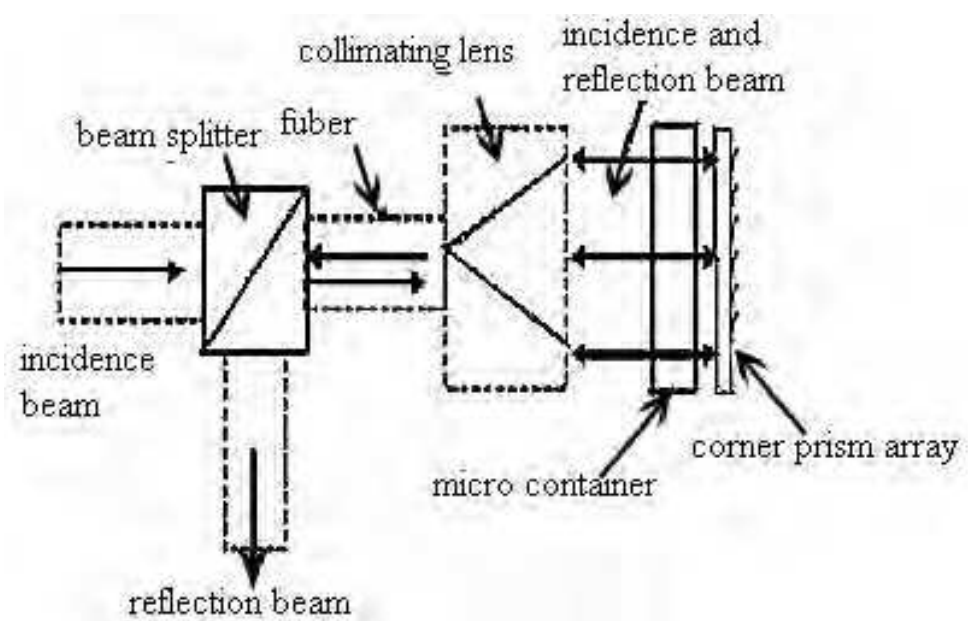

Fig. 6. Double optical path unit. 


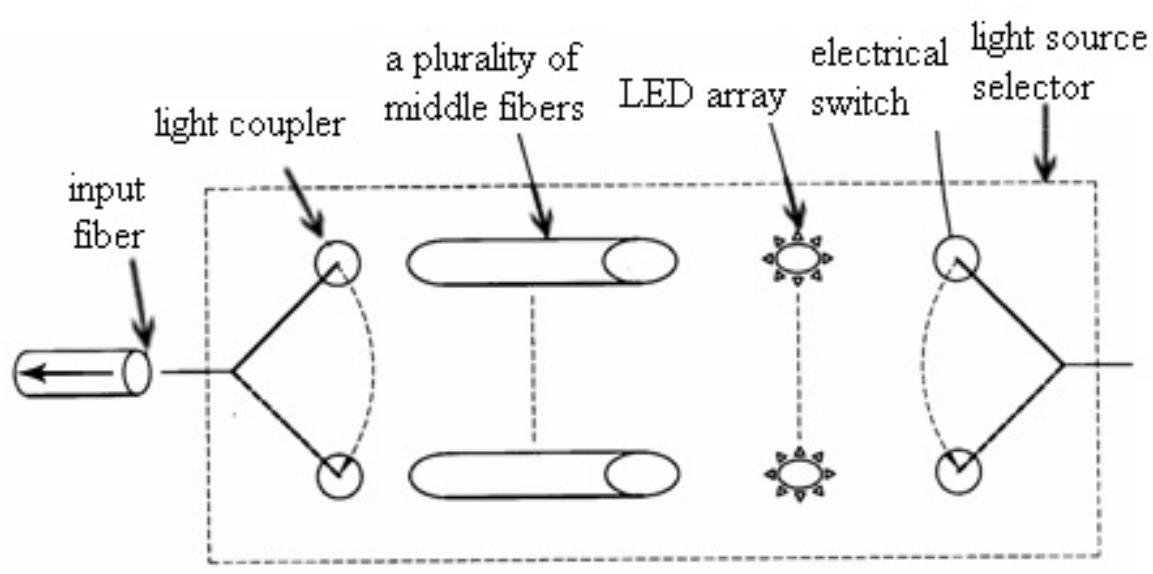

Fig. 7. Light source selector.

the density of a specific influenza virus, etc. Thus, this invention is multi-functional. Concerning the detector, it is used for detecting a final intensity of a received beam. The signal processor unit is used for comparing the detected final intensity of the sample with reference intensity so that an absorbance of the sample can be calculated. Therefore, the input fiber guides a first beam passing through the cube beam splitter of the beam splitting device and then through the two-way fiber to arrive to the collimator so as to expand as a second beam having another diameter approximately equal to said predetermined diameter; then the second beam continues to penetrate the micro container and becomes a third beam (The third beam is weaker than the second beam because some of the beam is absorbed by the sample). After reflecting by the corner cube array and passing through the micro container again, a fourth beam (the fourth beam is weaker than the third beam) is obtained. After passing through the collimator, the fourth beam becomes a collected fifth beam. The fifth beam enters the two-way fiber to arrive to the cube beam splitter of the beam splitting device and then to be reflected aside into the output fiber and finally to the detector so that the signal processor unit can calculate an absorbance of the sample, as shown in Fig. 8 . About the measurement principle of this research, once the beam penetrates the sample one time, the passing beam will be weakened. Thus, if it penetrates the sample twice, the total amount of decaying will be doubled. So, by measuring the amount of decaying, the absorbance can be determined. The corner prism array consists of many corner cube refractor. In this system, the sample contains a specific colored material (or label)/agent that already chemically reacted with an object that the user wants to measure. The shade of the colored sample is proportional to the degree of density of such object. By establishing the relationship between the shade and the density of the colored sample after chemically reacted with a suitable coloring agent (or label), the density of the sample can be determined by detecting its actual shade of the sample. In a bio-chemical test, usually a suitable coloring agent will be added to react with the object that we want to measure. Therefore, the shade of such color means the density of the object. The shade can be precisely measured by the 
voltage output of the detector. Of course, a graph about such relationship between the shade and the density can be established. A corner cube reflector is a retroreflector consisting of three mutually perpendicular, intersecting flat surfaces, which reflects parallel light ray back towards the source as shown Fig. 9. Fig. 9 (a) is contour of corner prism array. Fig. 9 (b) shows that corner cube are used to reflect light beam back to the original direction.

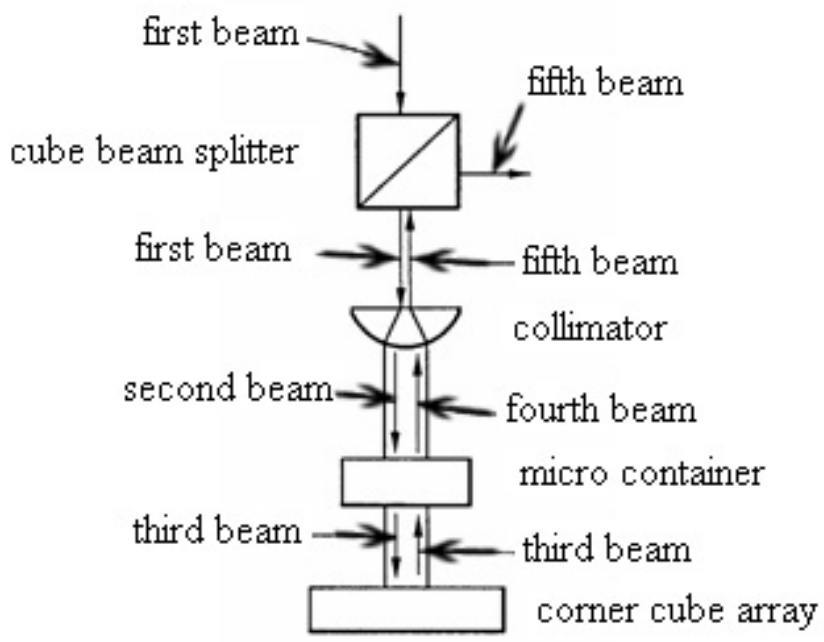

Fig. 8. The layout of double optical path.

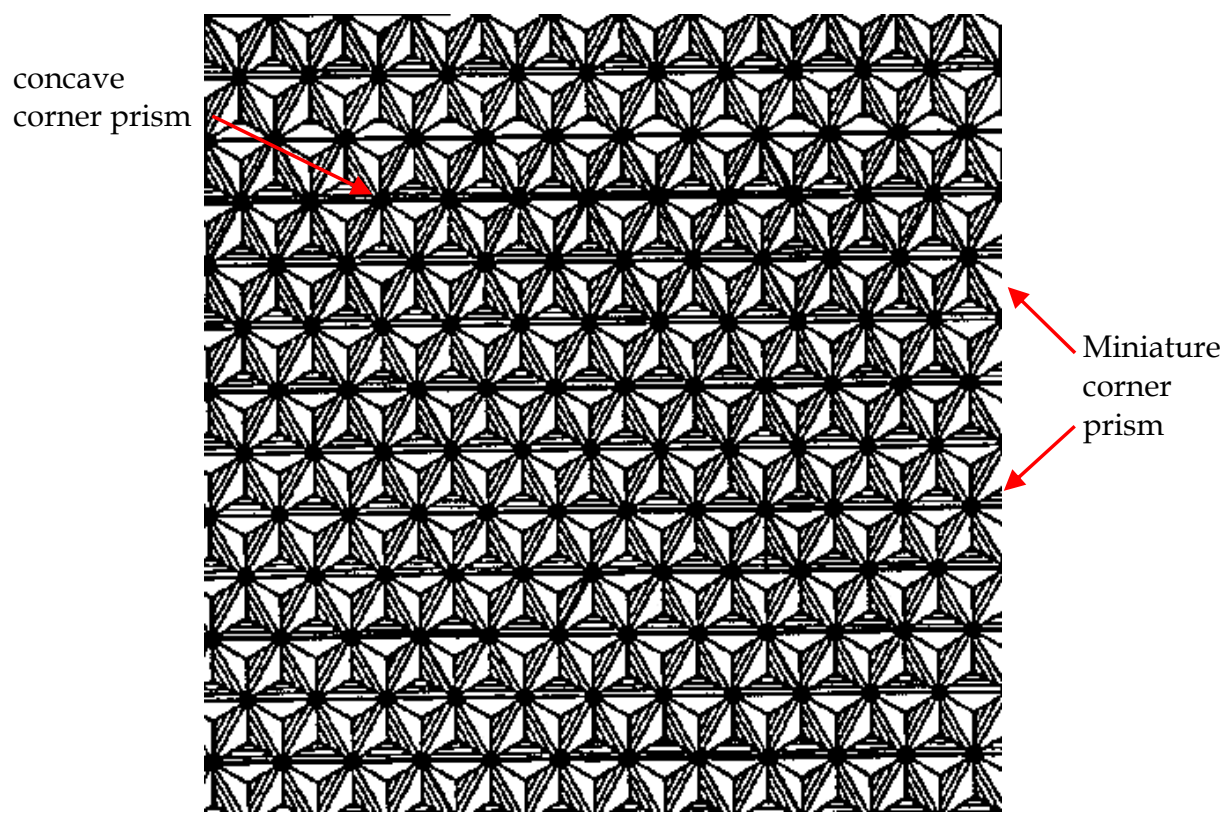

Fig. 9. (a) Contour of corner prism array (from US patent 6,206,565 B1). 


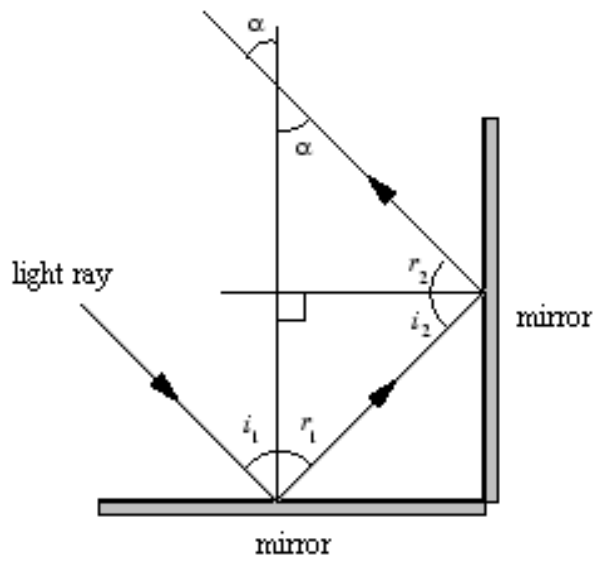

Fig. 9. (b) Parallel light path reflected by a corner cube.

A light ray incident from any direction in the plane perpendicular to both mirrors is reflected through $180^{\circ}$. We are effectively being asked to prove that $\mathrm{a}=i_{1}$, for any value of $i_{1}$ from trigonometry and the law of reflection. The light emitting diode (LED) is used as the light source in the optical transmitter/receiver unit. The LED emits the red light which passes through the collimating lens and becomes a collimated beam. After this collimated beam passes through the sample, it will be reflected back by corner prism array, and pass through the sample again. The reflected beam is focalized by collective lens of the receiver and be detected by the photodiode. By using the collimated beam with the corner prism array, the system does not require a very sensitivity optical alignment. The collective lens used in this system can form a sharper spot size and image all of the light emitted into the much larger area of it, therefore we can predict that the image illuminance will increase dramatically. We begin to calculate the axial image illuminance. An object region of area $A_{O}$ emits rays that are focused into an image region with area $A_{I}=M^{2} A_{O}$ is shown in Fig. $10 . M$ is linear magnification of collective lens. The image illuminance $E_{I}$ is the total flux divided by the image area. The flux is the product of the object's axial luminance, $\mathrm{L}_{\mathrm{O}}$, the object area, $\mathrm{A}_{\mathrm{O}}$, and, the solid angle subtended by the lens,

$$
\Omega_{L}=\frac{\pi D^{2}}{4 S_{O}^{2}}
$$

Thus the image illuminance is

$$
E_{I}=\frac{L_{O} A_{O} \Omega_{L}}{A_{I}}=\frac{\pi D^{2} L_{O}}{4 M^{2} S_{O}^{2}}=\frac{\pi D^{2} L_{O}}{4 S_{I}^{2}}
$$

Using thin lens equation, the linear magnification, $\mathrm{M}$, and the F-number, $\mathrm{N}$, we can transform Equation (2) into a more useful form which incorporates the lens F-number $\mathrm{N}$

$$
E_{I}=\frac{\pi D^{2} L_{O}}{4 f^{2}(1-M)^{2}}=\frac{\pi N^{2} L_{O}}{4(1-M)^{2}}
$$


Image illuminance is proportional to the object's axial luminance. The proportionality factor is a square of the lens F- number $(\mathrm{F} / \#)$, which can usually be read off the side of the lens barrel, and the magnification, which can be calculated by dividing the image size by the object size.

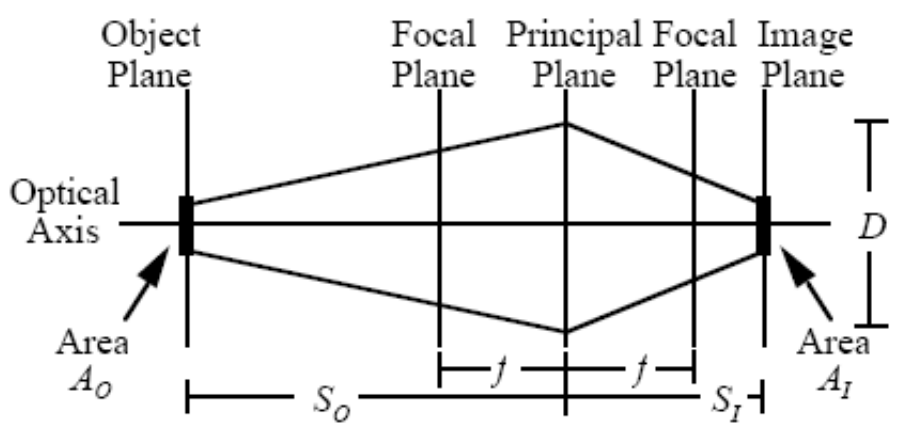

Fig. 10. Geometry of image illuminance (from “Introductory Optic" Ver. 2.04 1986-1987 Norman Wittels).

The system will also not suffer the effect of environment interference because of the use of pulse width modulation LED light. The peak emission's wavelength of the LED is matched with the peak absorption's wavelength of the Blue-Latex. The advantages for using the LED over the general light source such as household tungsten lamp are the small size, short response time, long lifetime, stable performance, etc. Also, the cost of design for the driver circuit using LED is lower than that of the laser-diode. As the peak emission wavelength $\lambda_{p}$ of LED has to be matched with the peak absorption wavelength $\lambda_{p}$ of the sample, we use the peak emission wavelength of the red light of $656 \mathrm{~nm}$ as the light source in this opticaltransmitter. LED is a kind of current-driven device, not a voltage-driven device. So, in order to generate stronger light beam for LED, we should provide larger forward bias current $\mathrm{I}_{\mathrm{F}}$, but the light beam intensity is not proportional to the provided current. As the forward bias current $\mathrm{I}_{\mathrm{F}}$ becomes larger, the dark current also becomes larger. When $\mathrm{I}_{\mathrm{F}}$ becomes larger and larger, the LED will go into the saturation state, and then it will be burnt out. Also, if LED works under the larger current for a long time, it will becomes overheated and age too soon. To prevent LED from the aging problem, we use the pulsed current to drive LED, i.e. at the fixed duration, the constant current is provided. We use the inverter (CD4069) with the capacitors to form the multi-vibrating circuit. The pulse light output is $46 \mu$ sec pulse duration which is obtained with the LED driving circuit, as shown in Fig. 11. [5]Fig. 12 shows the light output obtained with the LED circuit. The collimated beam of this device passes by the sample back and forth. Both the incident beam and the reflected beam are guided by the optical fiber. The reflected light will be focused on the detector by collective lens. The optical received terminal includes photodiode, filter circuit and amplifier, as shown in Fig. 13. [6] A potentiometer is placed before the filter circuit. By changing this, we can trim the sensitivity of the detector. To prevent the noise, such as the signal from the lighting lamp, from being amplified with the signal, we use a high pass filter comprised of capacitors and resistors to filter out the $120 \mathrm{~Hz}$ signal. Owing to the current generated by the photodiode is very small, and in order to be easily analyzed, we need to amplify the output voltage. The signal is amplified by using the amplifier LM324M and negative feedback. The 
ambient electric-magnetic interference (EMI) will effect the detection in the system. To prevent the EMI noise, we add a metal shield outside the circuit. The beam of the visible LED will be split into two beams. The first beam will go directly into the collimator to form the collimated beam. The collimated beam will pass through the samples, be reflected by the prism arrays to pass though the sample a second time before being finally detected by the photodiode. The other beam will go into the collimator, form collimated beam, and then be detected by the other photodiode without passing through the sample.

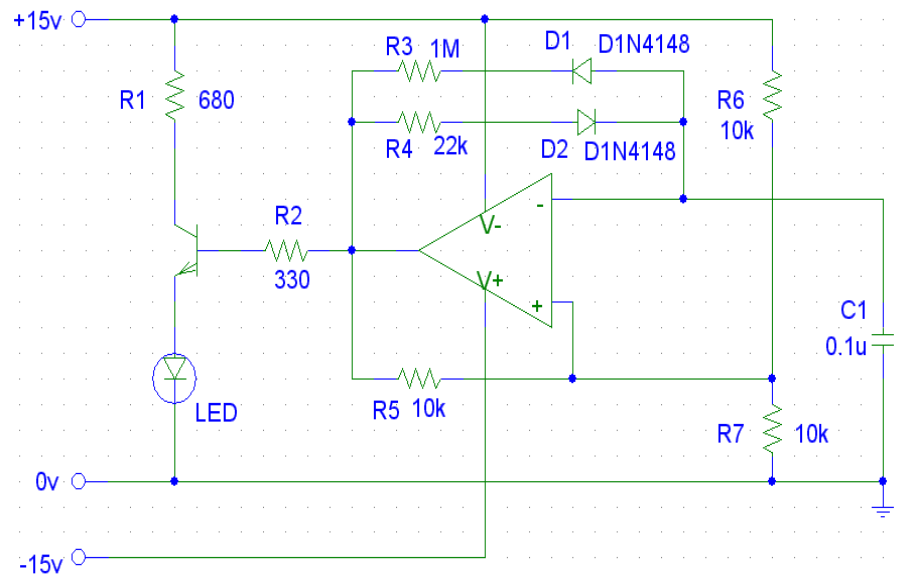

Fig. 11. LED drive circuit.

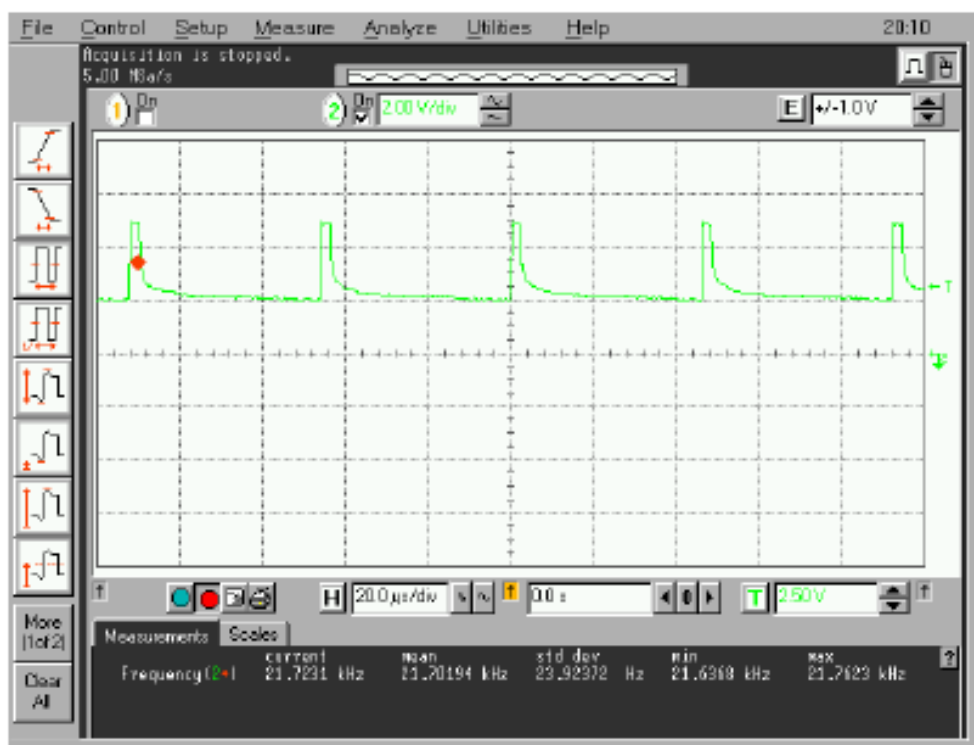

Fig. 12. The light output obtained with the LED circuit. 


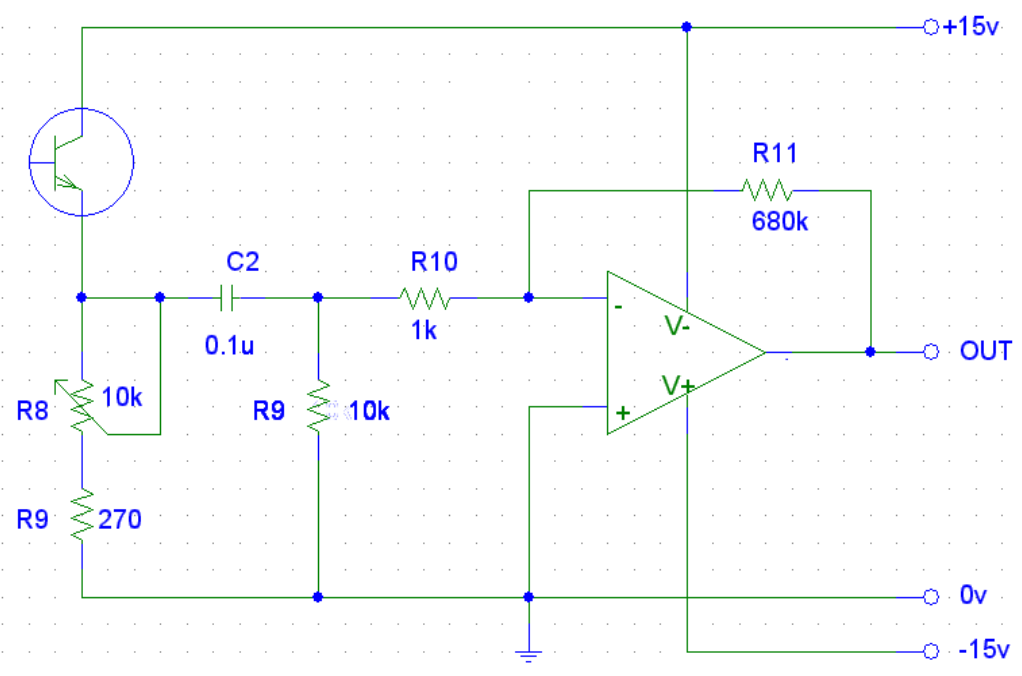

Fig. 13. Receiver circuit.

\section{Experimental results}

The new technique covers three important systems; these experiments are described as follows:

Experiment 1: the double optical path absorbance biometric system

The double optical path absorbance biometric system of is illustrated as Fig. 4 and double optical path unit as Fig. 6. The experimental parameters are as follows: The diameter of the optical fiber used as the light guidance is $1.00 \mathrm{~mm}$. The NA (numerical aperture) of multimodel plastic fiber is 0.44 . The peak emission wavelength $\left(\lambda_{\mathrm{p}}\right)$ of LED is $656 \mathrm{~nm}$ and spectral bandwidth $(\Delta \lambda)$ is $30 \mathrm{~nm}$, as shown in Fig. 14. The detector is Silicon photodiode. Blue-Latex solution has two peaks which absorption wavelength $(\lambda p)$ is $608 \mathrm{~nm}$ and $656 \mathrm{~nm}$; the rapidly declining curve of $400 \mathrm{~nm}$ is resulted from the Blue-Latex particles loss caused by scattering. The absorption spectrum of the Blue-Latex solution was shown in Fig. 15. As a result, the peak emission wavelength $\left(\lambda_{\mathrm{p}}\right)$ of LED has to be matched with the peak absorption wavelength $\lambda_{\mathrm{p}}$ of the sample. The procedures of the experiment are stated below: (1) Reagent: Blue-Latex solution is diluted by RO distilled water. (2) Using 500 micro liter ( $\mu \mathrm{l})$ micro container to load it, the effective optical path length of this solution is $5 \mathrm{~mm}$. (3) the peak absorption wavelength of the Blue-Latex solution is located on the peak emission wavelength of LED. As in Fig. 16(a), the result in this experiment reveals: if the concentration is above $10 \%$ or under $0.1 \%$, there is no detected signal. The situation is shown as Fig. $16(\mathrm{~b})$ shows that the linear range is only from $0.1 \%$ to $1 \%$ of concentration. From this experiment, we can learn the following: sensitivity of this device is not only related to the design, but also related to (1) the quality of optical alignment of double optical path unit, and (2) the parallel and flatness of the front and back of the micro container. From the results of the experiment, we see that the system achieved a sensitivity of $0.1 \%$, which is a five fold increase over a single optical path system with sensitivity of $0.5 \%$. The overall cost of the system is also significantly cheaper than a normal optical system that uses a spectrometer. A normal spectrometer system has a 
wide variety of uses and consists of complex and costly circuitry to support the diversity of the system. However, by designing the system that is more focused on the particular task of absorption detection, resulting in elimination of a microprocessor system, precision grating system, and the need of complex software, the cost of the system can be reduced by approximately $95 \%$. The reduction in the complexity and the reduction of the total amount of component in the system, the system ahs the additional benefit of reduced system size to that of one-fifth of a normal system. From now on, by changing its LED, we can detect different sample solutions without redesigning another detection circuit. The circuit of the double optical path absorbance biometric system is shown in Fig. 17 and the prototype of the double optical path absorbance biometric system, shown in Fig. 18, consists of double optical path unit, electronic unit, fiber and optic mount. The prototype of the single optical path absorbance biometric system is shown in Fig. 19, and the size of which is bigger than the double optical path absorbance biometric system because the optical path of former is more distant than the latter's.

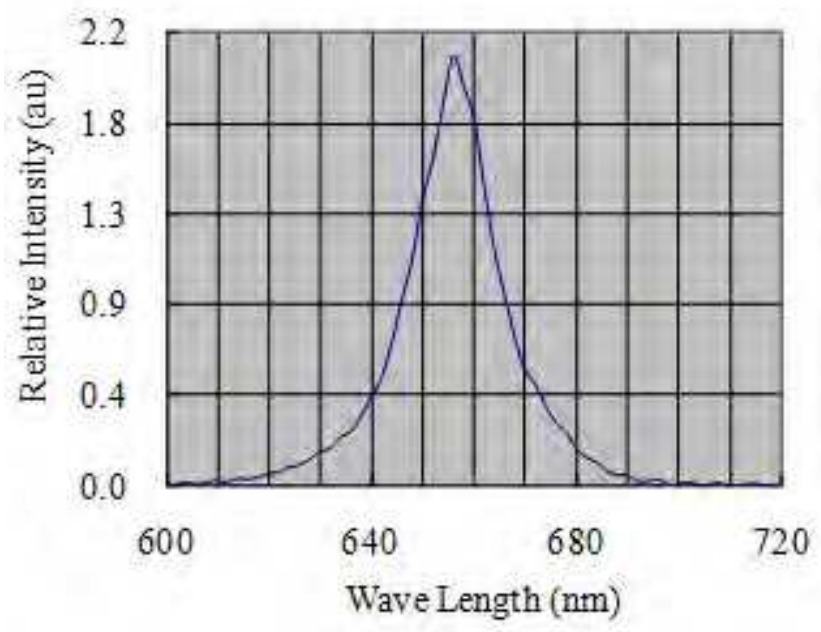

Fig. 14. Red LED emission spectrum. 


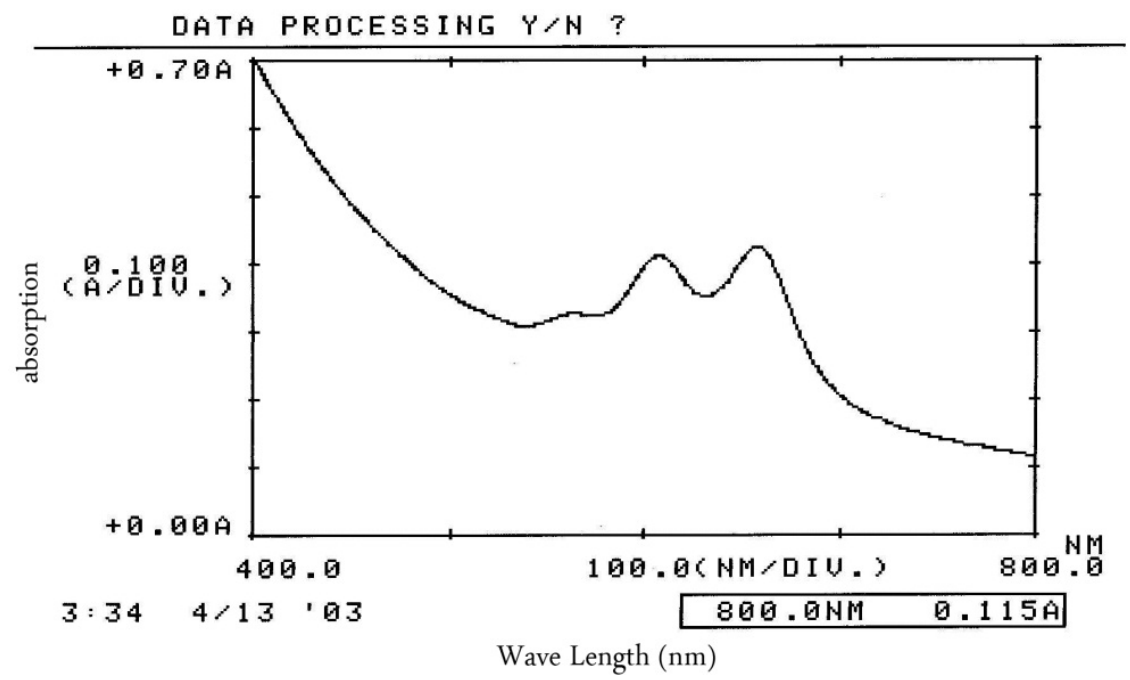

Fig. 15. Blue-Latex absorption spectrum.

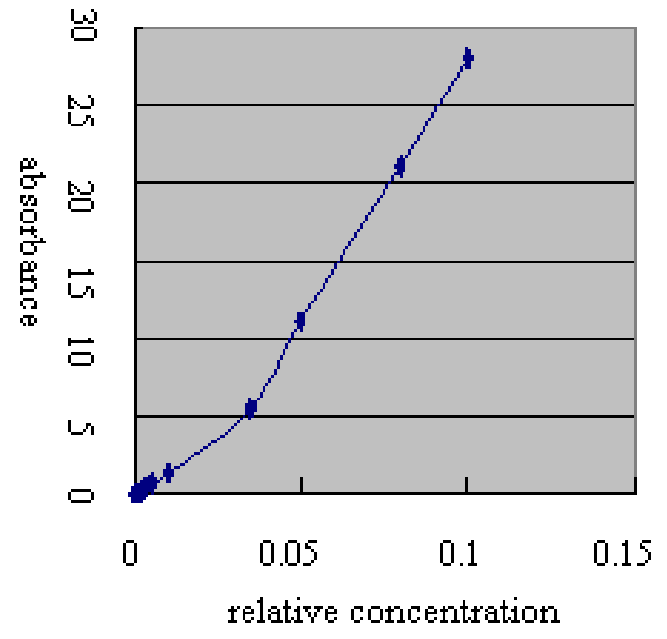

Fig. 16(a). Absorbance vs. relative concentration. 


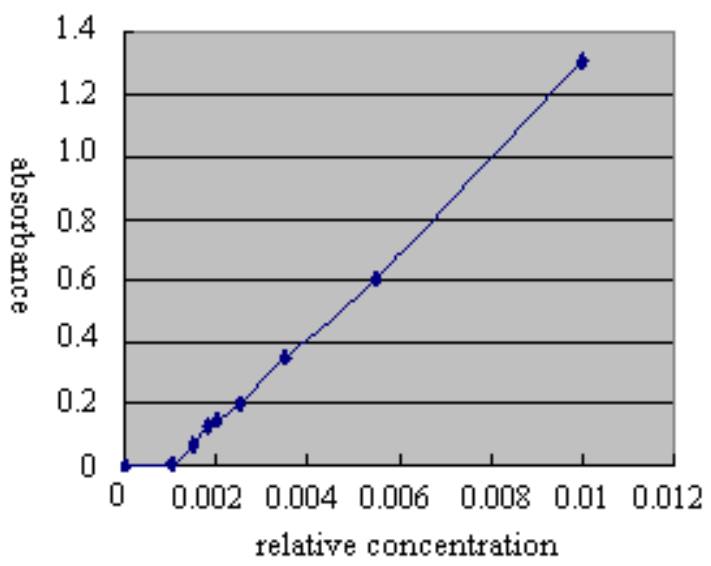

Fig. 16(b). Absorbance vs. relative concentration.

Experiment 2: the multi optical path absorbance biometric system After finishing the study of the double optical path biometric system, we continued the study of multi optical path biometric system for improving the detective sensitivity. Those circuits are all the same. The design parameters of multi optical path biometric system are not yet optimized at present, so the performance is not good. The design concept of multi optical path biometric system has descripted as follow.

The multi-optical path length absorbance biometric system designed in the way that the light emitted from light source goes through a specific path at least two times can detect the reduction amount of collimated beam of visible light passing through the label to know the absorbance of the sample. The object detected by this system is the label produces after biochemical reaction. After measuring absorbance of the label we can obtain the concentration of the sample. The objective for design of multi-optical path length absorbance is to increase absorption opportunities of the collimated beam and raise detective sensitivity of this system. The system comprise of a transmitter and receiver, a sample fluid and a multi-optical path unit as shown Fig.19. A transmitter includes a light source and driver. The receiver includes a detector, $\mathrm{O} / \mathrm{P}$ amplifier, $\mathrm{A} / \mathrm{D}$ converter, and processor. A multi- optical path unit includes back plane mirror, beam splitter, fold mirror, and output mirror. 


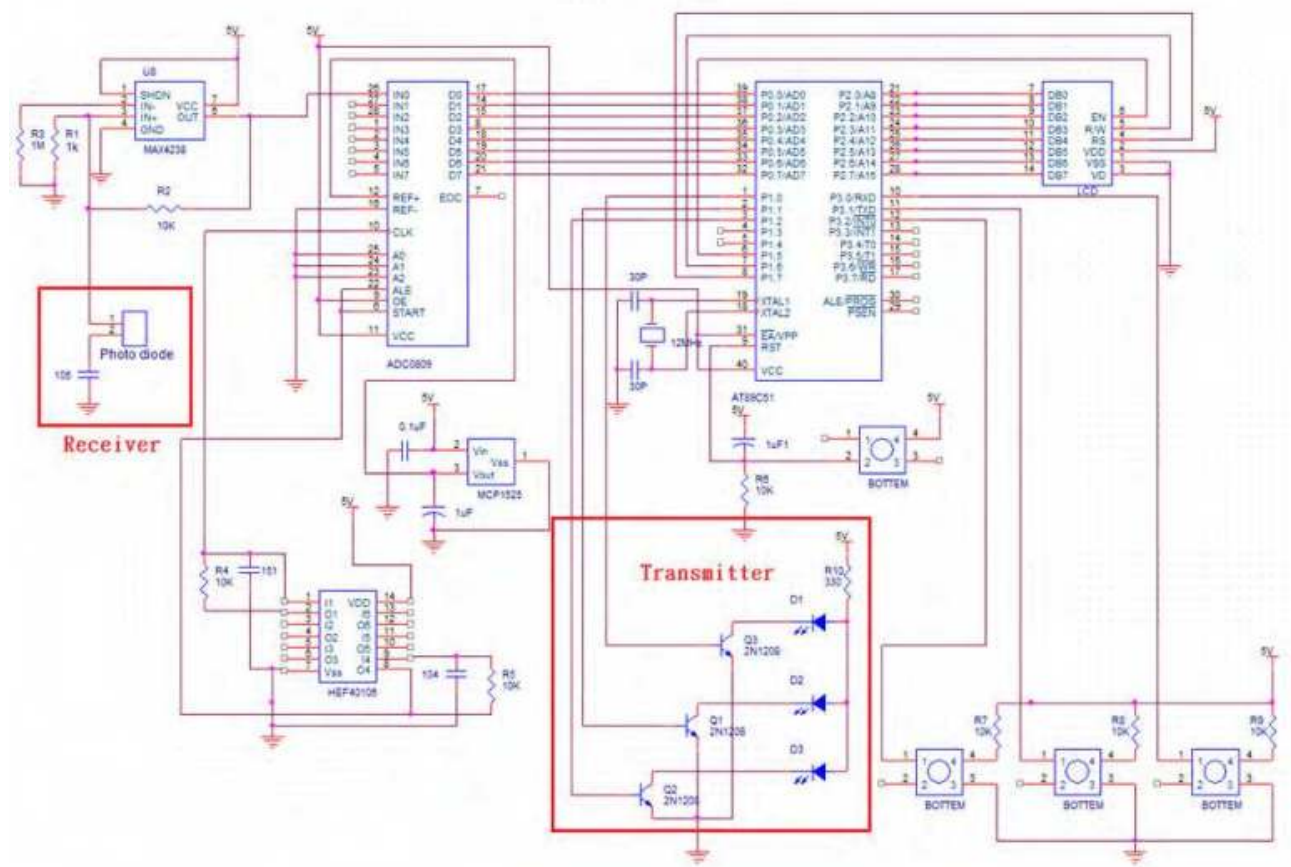

Fig. 17. The circuit of the double optical path absorbance biometric system.

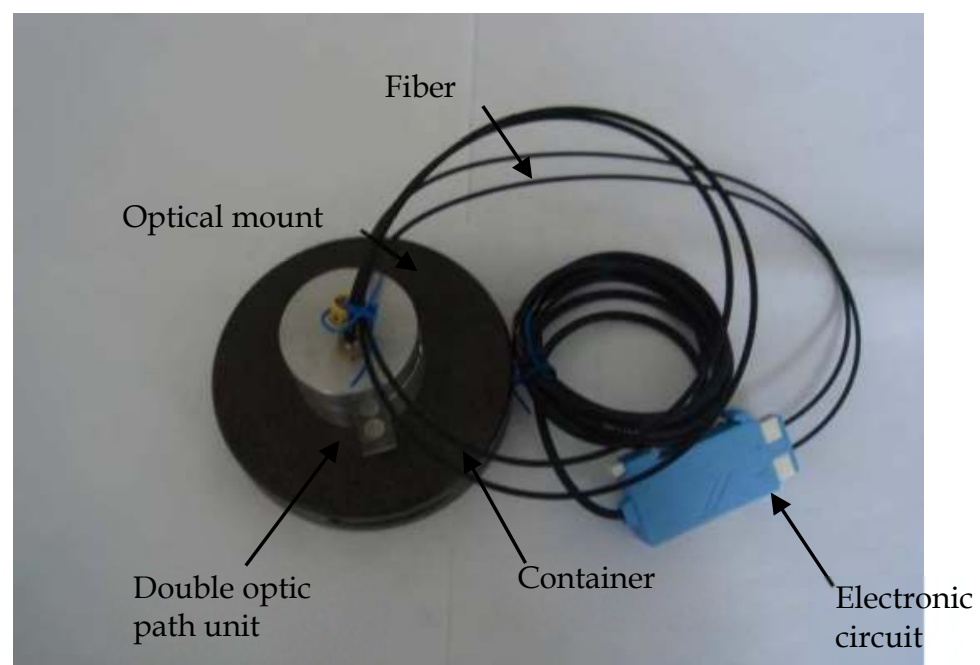

Fig. 18. Prototype of the double optical path absorbance biometric system. 


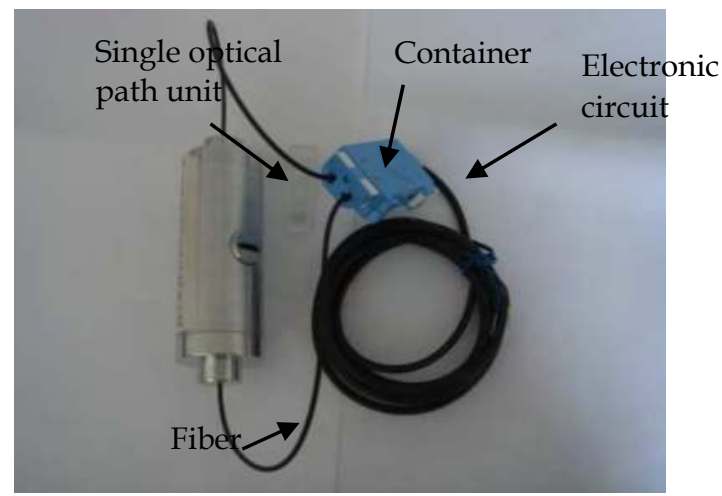

Fig. 19. Prototype of the single optical path absorbance biometric system.

The multi-optical path increases absorption opportunities of the collimated beam by sample. Comparing with one- or two-light path, the multi-optical path has highest detective sensitivity. Thus, it has the detective capability of the low concentration of the sample. This system has three advantages: (a) the multi-light path absorbance has low cost in terms of passive detective amplification, (b) the beam splitter and output mirror has combinations of different $\mathrm{R}$ and $\mathrm{T}$, which derive different detective sensitivity, (c) it need less the sample. Following you could find the light path within multi-optical path device as solid and dashed line trip in Fig. 20. The solid line trip is defined the collimated beam passing through beam splitter, fold mirror, sample, output mirror and then output to the detector of receiver.

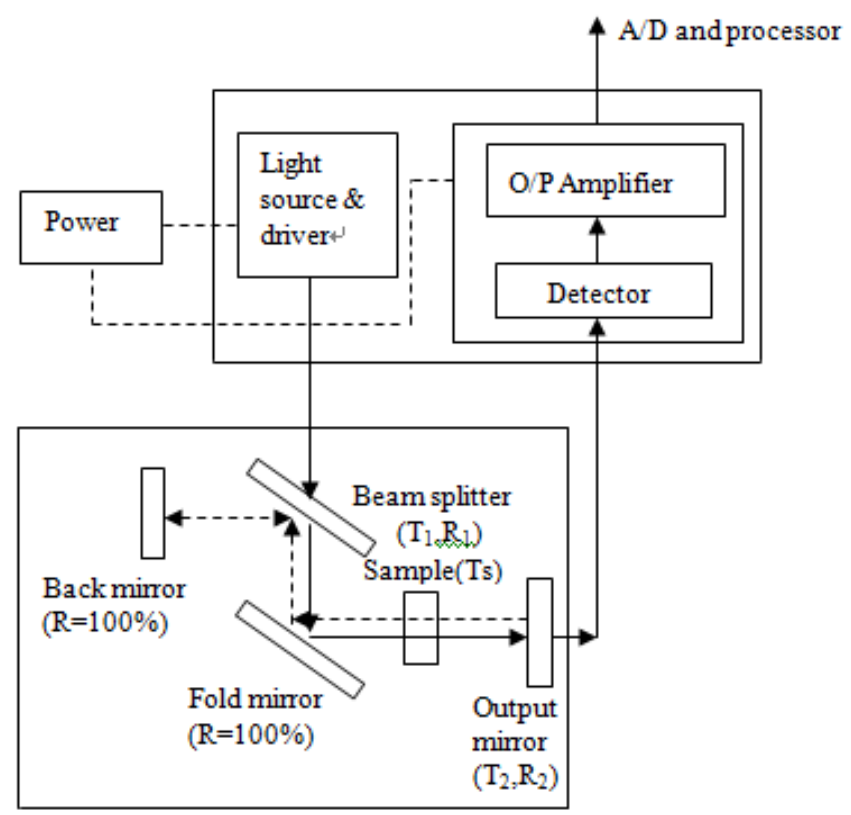

Fig. 20. The multi-optical path absorbance biometric system. 
The reflected beam will be back from output mirror and goes through sample, fold mirror, beam splitter and back mirror as a dashed line trip. The beam will undergo round trips and then the intensity of the beam will be reduced due to absorption of round trips as shown in Fig.20. The transmission of multi-optical path simulation is shown at Table 2. The simulation parameters $\mathrm{T}_{1}, \mathrm{~T}_{2}, \mathrm{R}_{1}, \mathrm{R}_{2}$, and $\mathrm{T}_{\mathrm{s}}$ are $50 \%, 30 \%, 50 \%, 70 \%$ and $70 \%$ respectively. The transmission of multi-optical path is 0.012. The transmission of one trip path is 0.105.From simulation results, absorbance is significantly increasing.

\begin{tabular}{|c|c|c|}
\hline & Solid line & Dash line \\
\hline 1. & $\left(T_{1} T_{S}\right)\left(R_{2} T_{S} R_{1}\right)$ & $\mathrm{T}_{1} \mathrm{~T}_{\mathrm{S}} \mathrm{T}_{2}$ \\
\hline 2 & {$\left[\left(\mathrm{~T}_{1} \mathrm{~T}_{\mathrm{S}}\right)\left(\mathrm{R}_{2} \mathrm{~T}_{\mathrm{S}} \mathrm{R}_{1}\right)\right]\left(\mathrm{R}_{1} \mathrm{~T}_{\mathrm{S}} \mathrm{R}_{2} \mathrm{~T}_{\mathrm{S}}\right)$} & {$\left[\left(\mathrm{T}_{1} \mathrm{~T}_{\mathrm{S}}\right)\left(\mathrm{R}_{2} \mathrm{~T}_{\mathrm{S}} \mathrm{R}_{1}\right)\right]\left(\mathrm{R}_{1} \mathrm{~T}_{\mathrm{S}} \mathrm{T}_{2}\right)$} \\
\hline 3. & {$\left[\left(\mathrm{~T}_{1} \mathrm{~T}_{\mathrm{S}}\right)\left(\mathrm{R}_{2} \mathrm{~T}_{\mathrm{S}} \mathrm{R}_{1}\right)\right]\left(\mathrm{R}_{1} \mathrm{~T}_{\mathrm{S}} \mathrm{R}_{2} \mathrm{~T}_{\mathrm{S}}\right)^{2}$} & {$\left[\left(T_{1} T_{S}\right)\left(R_{2} T_{S} R_{1}\right)\right]\left(R_{1} T_{S}\right)\left(R_{2} T_{S} R_{1}\right)\left(R_{1} T_{S} T_{2}\right)$} \\
\hline \multirow[t]{5}{*}{$\mathrm{n}$} & {$\left[\left(T_{1} T_{S}\right)\left(R_{2} T_{S} R_{1}\right)\right]\left(R_{1} T_{S} R_{2} T_{S}\right)^{(n-1)}$} & $\left(T_{1} T_{S} T_{2}\right)\left(R_{1}^{2} T_{S}^{2} R_{2}\right)^{n}$ \\
\hline & & $\mathrm{T}_{1} \mathrm{~T}_{\mathrm{S}} \mathrm{T}_{2}+$ \\
\hline & & {$\left[\left(T_{1} T_{S}\right)\left(R_{2} T_{S} R_{1}\right)\right]\left(R_{1} T_{S} T_{2}\right)+$} \\
\hline & & {$\left[\left(\mathrm{T}_{1} \mathrm{~T}_{\mathrm{S}}\right)\left(\mathrm{R}_{2} \mathrm{~T}_{\mathrm{S}} \mathrm{R}_{1}\right)\right]\left(\mathrm{R}_{1} \mathrm{~T}_{\mathrm{S}}\right)(\mathrm{R} 2 \mathrm{TSR} 1)(\mathrm{R} 1 \mathrm{TST} 2)+\ldots+$} \\
\hline & & $\left(T_{1} T_{S} T_{2}\right)\left(R_{1}^{2} T_{S}^{2} R_{2}\right)^{n-1}$ \\
\hline$\Sigma$ & & {$\left[\left(\mathrm{T}_{1} \mathrm{~T}_{\mathrm{S}} \mathrm{T}_{2}\right) /\left(1-\mathrm{R}_{1} \mathrm{R}_{1} \mathrm{~T}_{\mathrm{S}} \mathrm{T}_{\mathrm{S}} \mathrm{R}_{2}\right)\right]$} \\
\hline
\end{tabular}

Table 2. The transmission of multi-optical path simulation.

Experiment 3: the multi-RGB color sensor measurement system

Unlike previous two experiments detecting the sample of single wavelength, the multi-RGB color sensor measurement system detects the sample of multi-wavelength. We study the design of the multi-RGB color sensor absorbance biometric system for the visible range absorbance biometric detection. The color samples were scarcely obtained and the color ball is to substitute it. Color can be regarded as an intrinsic physical property of an object or as a visual sensation. As a sensation, it results from three different types of the receptor cells in the retina each of which responds to a different portion of the visual spectrum. As a physical property, color is determined by the wavelength distribution of the transmitted or reflected light. Given any three different colored sources of light, it is possible to mix them in proportions that will match any sample. Thus, a color transmission of sample can be specified in terms of $\mathrm{X}_{\mathrm{R}}, \mathrm{Y}_{\mathrm{G}}$, and $\mathrm{Z}_{\mathrm{B}}$, which are the amounts of the three primaries colors required to match the sample. For convenience, the ratio of the output voltage is commonly expressed in percent, as follows:

$$
X_{R}=R /(R+G+B)
$$




$$
\begin{aligned}
& Y_{G}=G /(R+G+B) \\
& Z_{B}=B /(R+G+B)
\end{aligned}
$$

where R,G, and B is the red, green, and blue light output voltage in RGB color photodiode sensor. This system uses seven RGB color sensors to detect the color sample and recognize the sample with data comparison technique. The white LED emits the visible light which passes through the color sample and detect by the RGB color sensor. The emission's spectrum of the LED is matched with the peak absorption's wavelength of the RGB color sensor. The advantages for using the LED are the small size, short response time, long lifetime, and stable performance. The three sub pixel sensor of the seven RGB color sensor has a total of 21 analog output channels. To manage the massive amounts of analog signal, the analog Multiplexers/De-multiplexer is connected to the output of the RGB color sensor. An operation amplifier is connected to the output of the analog Multiplexers/Demultiplexer to raise the small output signal to about tenfold, raising the contrast of this system. Before the signal enters microprocessor, the analog signals are converted into the digital signal by the A/D converter. The software in the microprocessor plans and arranges the digital signal, as well as compares the data for color recognition. The data base of the microprocessor has $\mathrm{X}_{\mathrm{R}}, \mathrm{Y}_{\mathrm{G}}$, and $\mathrm{Z}_{\mathrm{B}}$ of seven balls at the different environment conditions. When the microprocessor receives the interrupt command of the push bottom, the white LED emits visible light. The voice IC enable by the subprogram, produces a series of sounds corresponding to the color sample. The system in Fig. 21 is composed of the followings: (a) the seven RGB sensors show in Fig. 26, are group according to Reds, Greens and Blues. (b) The Analog Multiplexers/Demultiplexer and Operational amplifier, (c) the A/D converters and 2-input multiplexer (d) 8051 single chip microcontroller, single chip voice record and playback device and seven push button pieces(S1....S7).

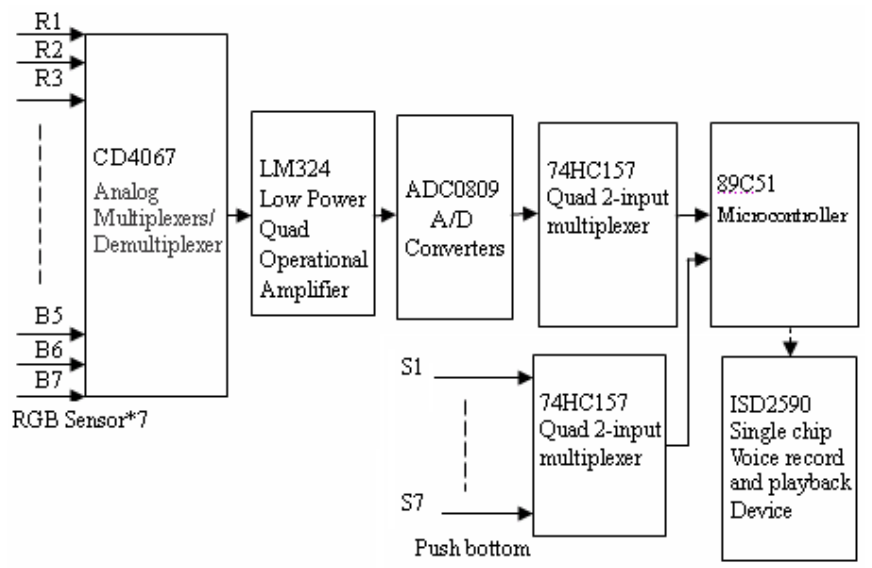

Fig. 21. Block diagram of system.

A photodiode has two terminals, a cathode and an anode. It has a low forward resistance (anode positive) and high reverse resistance (anode negative). Normal biased operation of most photodiodes calls for negative biasing. The active area of the device is the anode or positive biasing. The backside of the device is the cathode. Fig. 22 shows method of 
measuring light by measuring the photocurrent. Fig. 22 shows a basic circuit connection of an operational amplifier and photodiode. The output voltage $\mathrm{V}_{\text {out }}$ from DC through the lowfrequency region is 180 degrees out of phase with the input current. The feedback resistance $R_{f}$ is determined by input current and the required output voltage $V_{\text {out }}$. If, however, $R_{f}$ is made greater than the photodiode internal resistance $R_{\mathrm{sh}}$, the operational amplifier's input noise voltage input equivalent noise voltage and offset voltage will be multiplied by $\left(1+\frac{R_{f}}{R_{s h}}\right)$. This is superimposed on the output voltage $V_{\text {out, }}$ and the operational amplifier's bias current error will also increase. It is therefore not practical to use an infinitely large $R_{\mathrm{f}}$. If there is an input capacitance $C_{t}$, the feedback capacitance $C_{t}$ prevents high-frequency oscillations and also forms a low pass filter with a time constant $C_{f} \times R_{f}$ value.

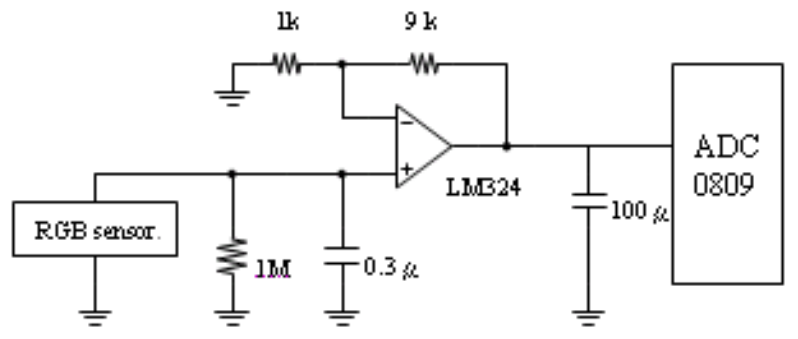

Fig. 22. Photodiode operation circuit.

The optical measurements software is capable of measuring chromaticity and luminance. The flow chart of software program is stated below:

1. Initiate 89C51 microprocessor and execute main program (as shown Fig. 23).

Step.1: check to see if button is push.

R3=0, the INTT0 interrupt button not push, Re-check register.

R3=1, the INTT0 interrupt button is push, Processor to next step.

Step.2: Read the digital signal from the Analog-to-Digital Converters into microprocessor memory.

Step.3: Calculate $\mathrm{X}_{\mathrm{R}}, \mathrm{Y}_{\mathrm{G}}$, and $\mathrm{Z}_{\mathrm{B}}$ for each sensor and compare it with $\mathrm{X}_{\mathrm{R}}, \mathrm{Y}_{\mathrm{G}}$, and $\mathrm{Z}_{\mathrm{B}}$ Data Table.

Step.4: After calculation, the Processor sends signal to the 74HC157 to switch the input signal from ADC0809 to the button.

2. When INTT1 interrupt button is push (see Fig. 24):

Step.1: Read the signal from the push button.

Step.2: Determine the specific button of the signal by matching the signal with the data in memory.

Step.3: ISD2590 produces the sounds that match the sensor reading for 3 second.

The conditions and specifications used for the experiment are listed in Table 3.This experiment use seven RGB sensors, seven high power white LED, seven difference color plastic balls, one polishing steel ball, and optoelectronic circuit board. The coloring of plastic ball is uniform. The spectral response of RGB sensors is shown Fig. 25. The hardware is shown as Fig. 26.The RGB Sensor and white LED is set in the two sides of the hole of color balls test device. The distance between them is about $40 \mathrm{~mm}$. 


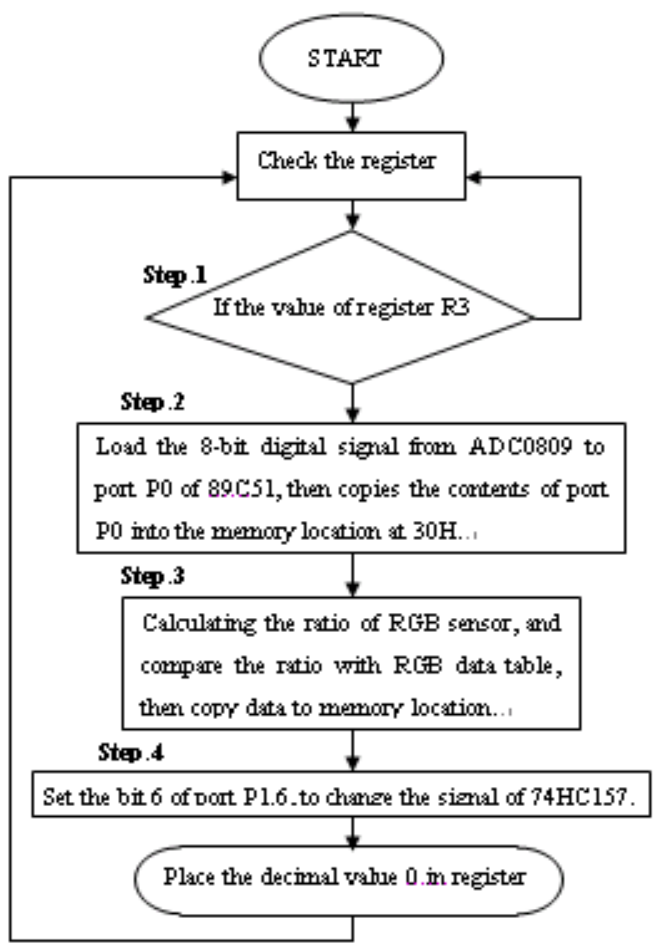

Fig. 23. Main program flow chart.

\begin{tabular}{|c|c|}
\hline $\begin{array}{c}\text { Operating } \\
\text { wavelength }\end{array}$ & $400 \mathrm{~nm} \sim 700 \mathrm{~nm}$ \\
\hline RGB Sensor & $\begin{array}{l}\text { (a) 3-channel (RGB) photodiode sensitive to the blue }(\lambda p=460 \mathrm{~nm}) \text {, } \\
\text { green }(\lambda p=540 \mathrm{~nm}) \text { and red }(\lambda p=620 \mathrm{~nm}) \text { regions of the spectrum. } \\
\text { (b) Active area: 3-segment (RGB) circular active area of } \varphi 2 \mathrm{~mm} . \\
\text { (c) spectral response as shown Fig.5. } \\
\text { (d) Non-reflective black sleeve. }\end{array}$ \\
\hline Plastic color ball & $\begin{array}{l}\text { The } X_{R}: Y_{G}: Z_{B} \text { of seven balls is showed as Table } 4 \text {. } \\
\text { Some of colour balls have four } X_{R}: Y_{G}: Z_{B} \text { due to the surface colour is } \\
\text { not uniform. But it won't affect systems recognition on colour balls. }\end{array}$ \\
\hline white LED & $\begin{array}{l}\text { (a) Emitting Color: White, } \\
\text { (b) Luminous Intensity } 1100 \text { mcd@ Forward Current 20mA, Reverse } \\
\text { Voltage 5volt. }\end{array}$ \\
\hline Dynamic range & $-0.3 \mathrm{~V} \sim 3.4 \mathrm{~V}$ \\
\hline Noise & Dark current $\sim 10 \mathrm{nA}$ \\
\hline $\begin{array}{l}\text { Environmental } \\
\text { intensity of } \\
\text { illumination }\end{array}$ & Luminous Intensity $\geqq 900 \mathrm{mcd}$ \\
\hline
\end{tabular}

Table 3. Experiment's conditions and specifications of this measurement system. 


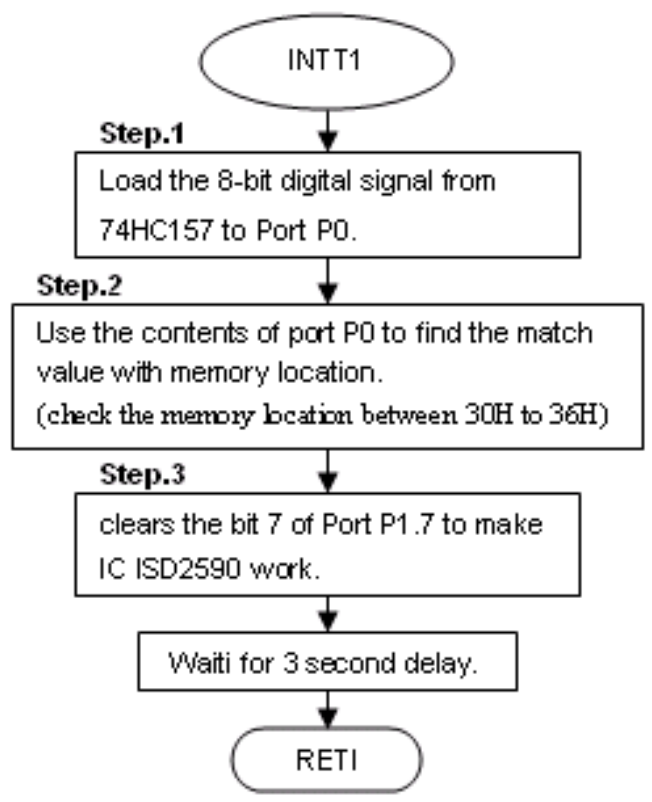

Fig. 24. Interrupts 1 subprogram flow chart.

Experiment procedure describes as follow:

1. Put color balls in the hole of color balls test device and ICE tester set up as shown in Fig. 7.

2. Built and record the look up table of $\mathrm{X}_{\mathrm{R}}$ : $\mathrm{Y}_{\mathrm{G}}$ : $\mathrm{Z}_{\mathrm{B}}$ (see tab.4 of color balls at the different environmental intensity of illumination.

3. When the system power on, the detection of color balls are ready.

4. When one color ball is press down, the push bottom switch is enabling and the color ball is detected.

5. The loudspeaker will send out corresponding sounds of the color ball.

6. Repeat fifty times from (4) to (5).

According to the arrangement, there are seven kinds of color ball producing 5040 combinations in this system. The detection error of the system is less than $0.1 \%$.

It is necessary, in general, to take into account the geometry of the source-detector system to calculate the signal incident on the detector. The usual case is that the detector only intercepts a small fraction of the radiated signal, however. Assuming that even a rough surface can be treated as a collected of plane surfaces that the incremental power incident on the portion of the detector considered $\left(\mathrm{dA}_{d}\right)$ due to the portion of the source under consideration $\left(\mathrm{dA}_{\mathrm{s}}\right)$ is given by $d \Phi=\left[L_{s} d A_{s} \cos \theta_{s} d A_{d} \cos \theta_{d}\right] / R^{2}$.If the field of view of the detector system is greater than the solid angle subtended by the source at the detector, a large uniform background of radiance $L_{B}$ contributes a radiant power of $\Phi_{b}=L_{B} A_{d}\left(\Omega_{B}-\Omega_{S}\right)$. When $\Omega_{B}>\Omega_{S}$ then $\Omega_{B}$ represents the solid angle field of view intercepting the background. The effect of field of view of the detector system on the irradiance due to an extended uniform background is mathematically similar to the calculation, except that it is carried out over a symmetrical field of view of halfangle $\theta_{1 / 2}$ rather than over a full hemisphere: 
$\mathrm{E}=\mathrm{L}_{\mathrm{s}} \int_{\theta 1 / 2} \int_{2 \pi} \cos \theta \times \sin \theta \mathrm{d} \theta \mathrm{d} \varphi, \mathrm{E}=\Pi \mathrm{L}_{\mathrm{s}} \sin ^{2} \theta_{1 / 2}$

Consider the two cases (A and B) of a detector directly irradiated by (A) an extended source with field of view restricted by a circular stop and (B) a detector radiated by a concentrating lens that has $\tau=1$ and no aberrations.

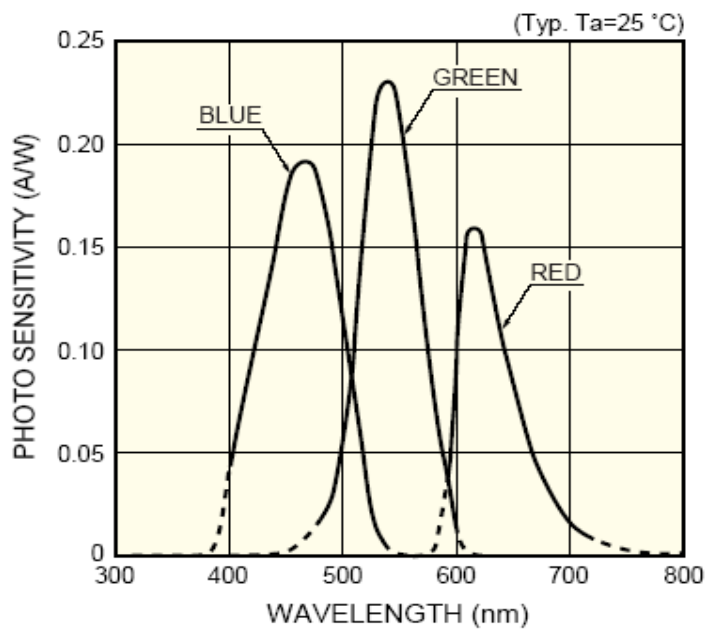

Fig. 25. The spectral response of RGB Sensor.

\begin{tabular}{|c|c|c|c|c|}
\hline Color ball & \multicolumn{4}{|c|}{$\mathrm{X}_{\mathrm{R}}: \mathrm{Y}_{\mathrm{G}}: Z_{\mathrm{B}}$} \\
\hline Red & $4: 3: 3$ & $4: 2: 4$ & $3: 3: 4$ & $3: 3: 4$ \\
\hline Orange & $5: 2: 2$ & $4: 2: 3$ & $4: 3: 3$ & $4: 2: 3$ \\
\hline Yellow & $4: 3: 2$ & $3: 3: 2$ & $4: 3: 2$ & $3: 3: 2$ \\
\hline Green & $3: 3: 3$ & $4: 3: 4$ & $4: 4: 3$ & $4: 4: 4$ \\
\hline Blue & $2: 2: 4$ & $2: 3: 5$ & $2: 3: 4$ & $2: 2: 4$ \\
\hline Indigo & $2: 2: 5$ & $1: 2: 6$ & $1: 1: 7$ & $1: 1: 7$ \\
\hline Purple & $3: 2: 4$ & $3: 2: 4$ & $3: 2: 4$ & $3: 2: 4$ \\
\hline
\end{tabular}

Table 4. The $\mathrm{X}_{\mathrm{R}}: \mathrm{Y}_{\mathrm{G}}: \mathrm{Z}_{\mathrm{B}}$ table of colour balls.

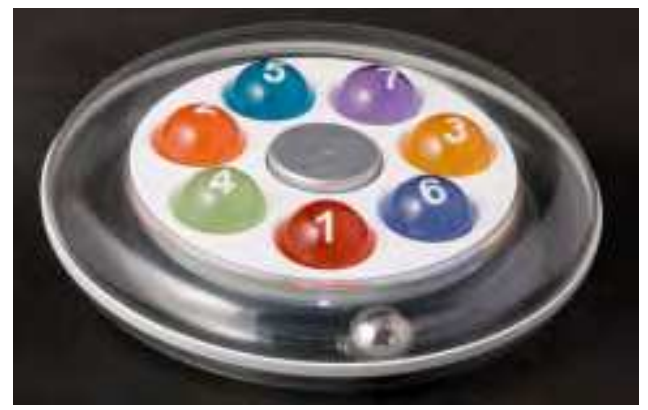

Fig. 26. The color balls test device. 
The key features of the system have :(1) Non-contact luminance and chromaticity measurement for color recognition.(2) Memory for storing 7 channels of reference color data recognizable.(3) High-quality single-chip voice IC to increase the recognizable data output. (4) Convenient user interface that switches the mode select by a single button. (5) Noise immunity: RFI and light source. Developed with the most advanced micro-processor, data comparison technique and the technology of optoelectronic detection and circuit design, the devise is capable of performing accurate stable and high speed color tests. According to the arrangement, there are seven kinds of color ball producing 5040 combinations in this system. The detection error of the system is less than $0.1 \%$.

\section{Conclusion}

This paper designed the high-resolution visible portable biometric system to measure the specific portions of the spectrum that feature sharper and better-resolved bands - the first time to use double optical path technique. This spectrum region is key for the qualitative and quantitative analysis of the gold colloid and blue latex solution. Miniature, rugged, and reliable, portable biometric technology has immediate application in industrial quality assurance and control, particularly in the emerging field of distributed process analytical spectroscopy in the chemical, food industry and pharmaceutical industries. The portable biometric system offer high speed, signal-to-noise, and resolution comparable to a traditional spectrophotometer.

\section{Acknowlegdments}

This research was supported by National Science Council of Taiwan (ROC) under contract No. NSC100-2623-E-035-001-D.

\section{Reference}

[1] Reinoud F. Wolffenbuttel, "State-of-the-Art in Integrated Optical Microspectrometers", IEEE Trans. Instrum. Meas.,vol.53, pp.197-202,2004.

[2] P. C. Montgomery, D. Montaner, O. Manzardo, M. Flury and H. P. Herzig, "The metrology of a miniature FT spectrometer MOEMS device using white light scanning interference microscopy", Thin Solid Films, vol.450, pp.79-83,2004.

[3] Der-Chin Chen,"Portable Biometric system of High sensitivity absorption detection", Journal of Microwave and Optical Technology letters ,vol.50 (4), pp.868-871, 2008.

[4] Der-Chin Chen, Chi-Chieh Hsieh, Huang-Tzung Jan and Huei-Kai Lai, "High presition multi-color sensor measurement system", International Conference on Manufacturing and Engineering Systems, pp.79-83,2009(MES2009)

[5] Mark I. Montrose, "EMC and the printed circuit board : design, theory, and layout made simple" , IEEE Press,pp.13-14, 1999.

[6] Y.D.Lin, C.D. Tsai, H .H. Huang, D.C. Chiou, and C .P. Wu " Preamplifier with a SecondOrder High-Pass Filtering Characteristic", IEEE Trans. Biomed. Eng., Vol. 46, pp. 609-612, 1999. 


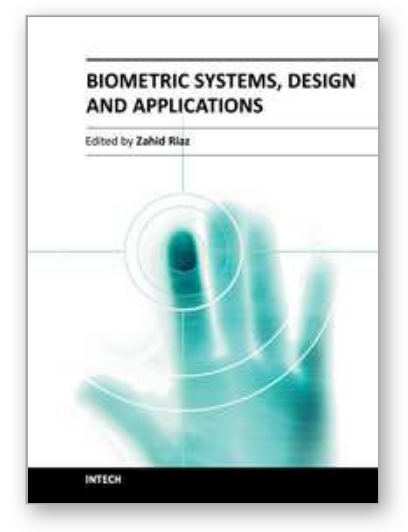

\author{
Biometric Systems, Design and Applications \\ Edited by Mr Zahid Riaz
}

ISBN 978-953-307-542-6

Hard cover, 262 pages

Publisher InTech

Published online 21, October, 2011

Published in print edition October, 2011

Biometric authentication has been widely used for access control and security systems over the past few years. The purpose of this book is to provide the readers with life cycle of different biometric authentication systems from their design and development to qualification and final application. The major systems discussed in this book include fingerprint identification, face recognition, iris segmentation and classification, signature verification and other miscellaneous systems which describe management policies of biometrics, reliability measures, pressure based typing and signature verification, bio-chemical systems and behavioral characteristics. In summary, this book provides the students and the researchers with different approaches to develop biometric authentication systems and at the same time includes state-of-the-art approaches in their design and development. The approaches have been thoroughly tested on standard databases and in real world applications.

\title{
How to reference
}

In order to correctly reference this scholarly work, feel free to copy and paste the following:

Der Chin Chen (2011). Portable Biometric System of High Sensitivity Absorption Detection, Biometric Systems, Design and Applications, Mr Zahid Riaz (Ed.), ISBN: 978-953-307-542-6, InTech, Available from: http://www.intechopen.com/books/biometric-systems-design-and-applications/portable-biometric-system-ofhigh-sensitivity-absorption-detection

\section{INTECH}

open science | open minds

\author{
InTech Europe \\ University Campus STeP Ri \\ Slavka Krautzeka 83/A \\ 51000 Rijeka, Croatia \\ Phone: +385 (51) 770447 \\ Fax: +385 (51) 686166 \\ www.intechopen.com
}

\author{
InTech China \\ Unit 405, Office Block, Hotel Equatorial Shanghai \\ No.65, Yan An Road (West), Shanghai, 200040, China \\ 中国上海市延安西路65号上海国际贵都大饭店办公楼 405 单元 \\ Phone: +86-21-62489820 \\ Fax: $+86-21-62489821$
}


(C) 2011 The Author(s). Licensee IntechOpen. This is an open access article distributed under the terms of the Creative Commons Attribution 3.0 License, which permits unrestricted use, distribution, and reproduction in any medium, provided the original work is properly cited. 